\title{
AGREGADOS TUBULARES EM CASO DE ATROFIA ESPINHAL CRONICA PROXIMAL
}

\author{
LINEU CESAR WERNECK * \\ CARLOS EDUARDO SILVADO ** \\ CARLOS ALBERTO BOER **
}

As biópsias musculares, quando processadas pela histoquímica, revelam alterações que normalmente passariam despercebidas aos métodos rotineiros de coloração após inclusão em parafina. Isto permitiu que nos últimos anos fossem descritas várias alterações musculares, descobertas unicamente por este método, o qual permite uma análise do comportamento enzimático das fibras musculares e de suas inclusões 5,11 .

Dentre estas alterações musculares, estudadas principalmente pela histoquimica, encontram-se os "central core", corpúsculos nemalínicos, "targets", "whorls", "moth-eaten", deficiência de miofosforilase, "grouping", atrofia ou predomínio de um tipo de fibra, fibras angulares escuras, acúmulo de lipídios e glicogênio, agregados mitocondriais e tubulares ${ }^{5,11}$. Estes últimos, foram descritos pela primeira vez por King Engel em 1964 e atualmente já existem diversos estudos histoquímicos e ultraestruturais que tentam elucidar a sua origem $^{8}$

A fim de contribuir para a compreensão destas estruturas, estamos relatando um caso de atrofia muscular crônica proximal ${ }^{23}$, onde foram encontrados agregados tubulares em biópsias musculares.

\section{OBSERVAGAO}

EZ, registro HC-PR 323068, 34 anos de idade, sexo masculino, cor branca, admitido com queixas de diminuição de força muscular e dificuldade para levantar peso. Referia o paciente que desde a infancia apresentava diminuição da força muscular, de evolução progressiva, mais intensa nos últimos dois anos. Alos 13 anos de idade ,apresentou crises convulsivas tônico-clônicas generalizadas, algumas vezes acompanhadas de alucinações visuais, sensaçăo de perseguição e agressividade. $\mathrm{Na}$ ocasiåo, iniciou tratamento com fenobarbital e difenilhidantoina e as crises tornaram-se mais raras, tendo a última ocorrido há 5 meses. Vem usando estas medicações nestes 20 anos. Relata história de teniase. Aos 20 anos de idade, sofreu traumatismo de ombro com subluxação da articulaçãio escapulo-humeral direita, perdendo parcialmente a mobilidade desta articulaçáo. Aos 25 anos de idade, foi avaliado por neurologista devido as crises convulsivas, sendo encontrado naquela ocasiăo diminuição da força muscular nos membros superiores, com presença de atrofia muscular proximal, fasciculaçoses, escoliose e reflexos profundos hiperativos. O liquido céfalorraquidiano obtido por punção sub-occipital, apresentava proteina de $31 \mathrm{mg} / \mathrm{dl}$, com leve opalescência à reação

Trabalho realizado na Disciplina de Neurologia do Departamento de Clínica Médica da Universidade Federal do Paraná, Curitiba, PR: "Professor Assistente; **Residentes. 
de globulinas. O paciente nega doença semelhante na familia e refere uso moderado de álcool. Exame fisico - Limitação da mobilidade da articulação escapulo-humeral direita. Exame neurológico - Paciente bem orientado, mas com atenção reduzida. Capacidade de cálculo, memória e julgamento normais. Labilidade do humor, com riso frequente e imotivado. Nervos cranianos: Diminuição da força nos músculos esternocleidomastoideos. Sistema motor: hipotrofia da musculatura da cintura escapular, mais evidente na regiăo posterior dos braços, ombros e músculos peitorais, com rasciculações nestes últimos. A força muscular, classificada de acordo com o MRCM era grau 3 no triceps e deltoide dirsito, grau 4 nos trapézios, deltjide esquerdo, supraespinhoso, biceps, extensores do carpo, iliopsoas, quadriceps, biceps surais e grau 5 nos demais músculos. Hipotonia generalizada. Coordenação normal. Reflexos profundos hiperativos e simétricos nos membros superiores e inferiores. Reflexos superficiais normais, com presença de palmomentonianos e nasolabial bilateralmente. sistema sensitivo normal. Marcha: ocasionais oscilações laterais e inclinação do tronco para a frente e para a direita.

Investigaço - Hemograma, VHS, mucoproteinas, proteina $\mathrm{C}$ reativa, fatores antinucleares, células L.E., sódio, potássio, cloro, cálcio, fósforo, uréia, creatínina, glicemia de jejum, eletroforese de proteinas, $17 \mathrm{KS}$ e $17 \mathrm{OH}$ urinários, P.B.I., colesterol e V.D.R.L. normais. Creatina-fosfokinase $11 \mathrm{U} . S i g m a / m l$, dehidrogenase lática 280 $\mathrm{U} . \mathrm{BB} / \mathrm{ml}$ aldolase $25 \mathrm{U} . \mathrm{SL} / \mathrm{ml}$, transaminase oxaloacética $24 \mathrm{U} . \mathrm{RF} / \mathrm{ml}$ e transaminase glutamico-pirúvica $14 \mathrm{U} . \mathrm{RF} / \mathrm{ml}$. Liquido céfalorraquidiano lombar, com pressão inicial de $80 \mathrm{~mm}$ de água, provas de permeabilidade normais; 3 células/mm3, glicose 106 $\mathrm{mg} / \mathrm{dl}$, proteinas $17 \mathrm{mg} / \mathrm{dl}$, reações para globulinas, Wasserman e Weinberg negativas. Tomografia axial computadorizada, eletrencefalograma e eletrocardiograma normais.

Eletromiografia - Foram estudados os músculos biceps, primeiro interósseo, reto anterior, tibial anterior e extensor comum dos dedos, revelando ausência de potenciais durante o repouso; durante a contração voluntária, existia aumento da duração e amplitude média dos potenciais, com excesso de polifásicos longos. Redução do recrutamento aos esforços em todos os músculos testados. Não foram verificados potenciais polifásicos curtos. Velocidade de condução nervosa motora no peroneiro foi de 42 metros/segundo, no ulnar de 53,5 metros/segundo e, no mediano esquerdo, 54,0 metros/segundo.

Histoquimica - Biópsia de músculos realizada com anestesia local, sendo os fragmentos fixados com tragacanth, congelados em nitrogenio liquido a - 1700 C, cortados em criostato a $-200 \mathrm{C}$, com 8 micras de espessura. Submetidos às colorações do tricromo de Gomori modificado por Engel e Cunninghan, hematoxilina e eosina, "oil red O",
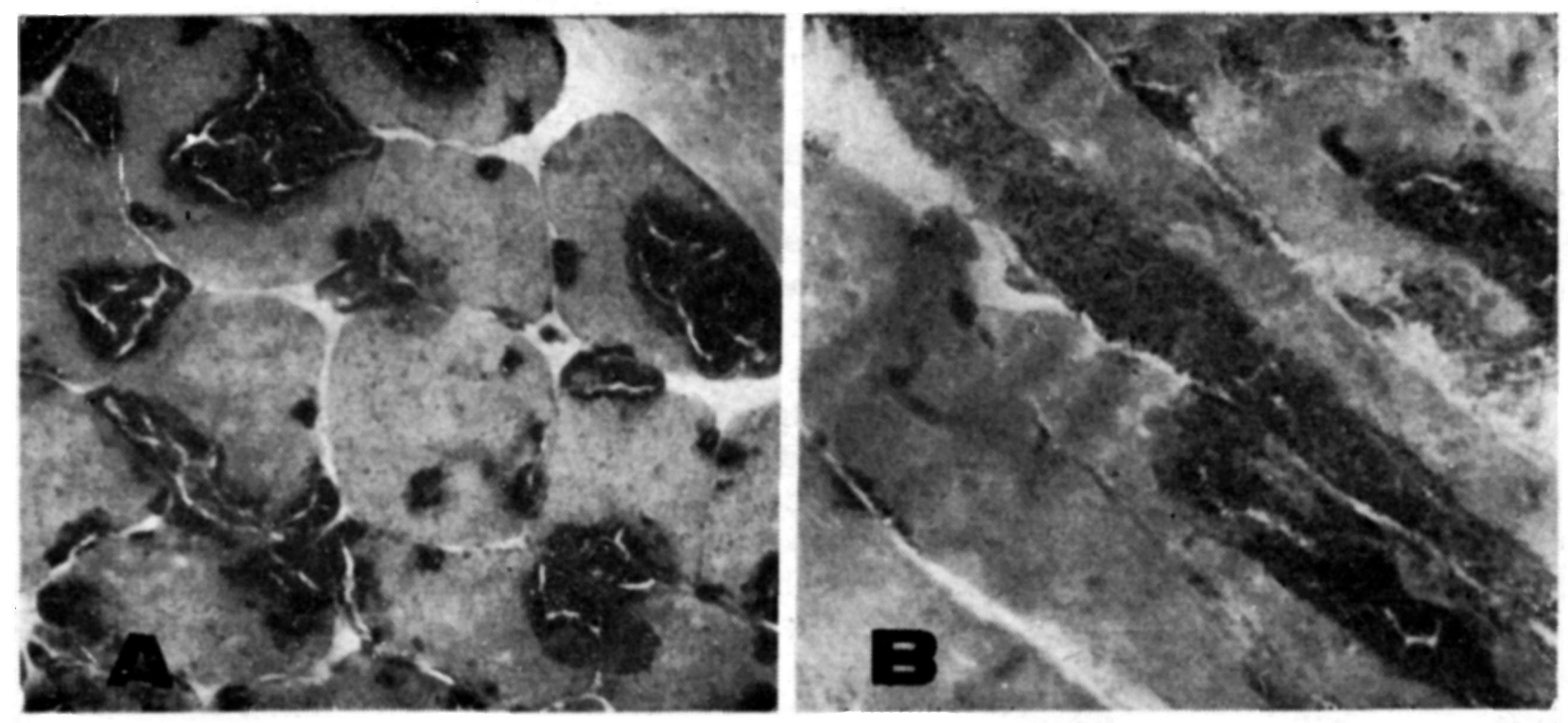

Frig. 1 - Agregados tubulares em caso de atrofia espinhal cronica proximal (tricromo de Gomori modificado, 450X): em A, corte transversal; em $B$, corte longitudinal. 

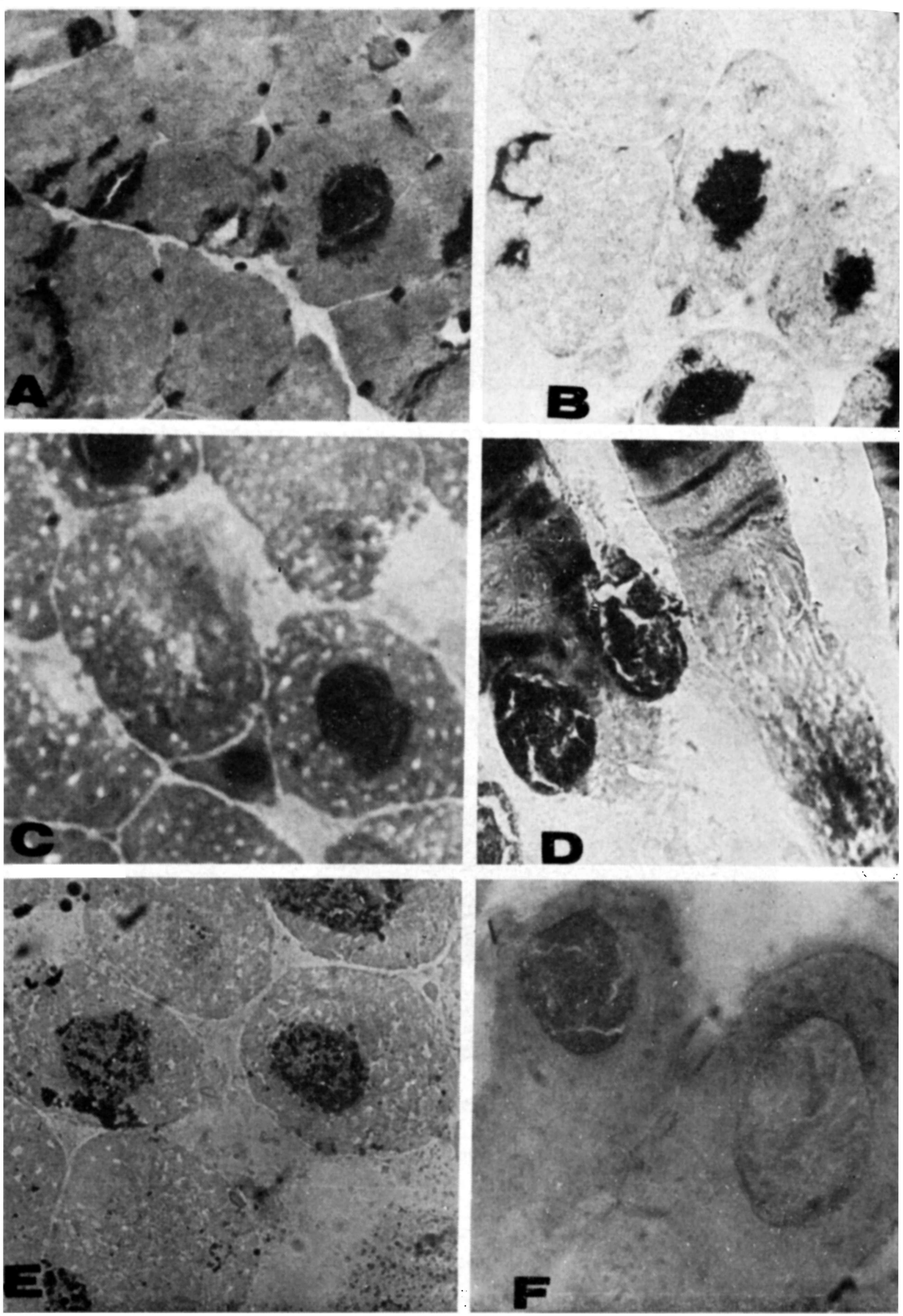

Fig. 2-Agregados tubulares em caso de atrofia espinhal cronica proximal (cortes transversas, 450X): $6 \mathrm{~m}$ A, tricromo de Gomori modificado; em $B, D P N H$-diaforase; em $C$, esterase inespecifica; em $D$, miofosforilase; em E, "oil red $O$ "; em $F, P . A .8$. 

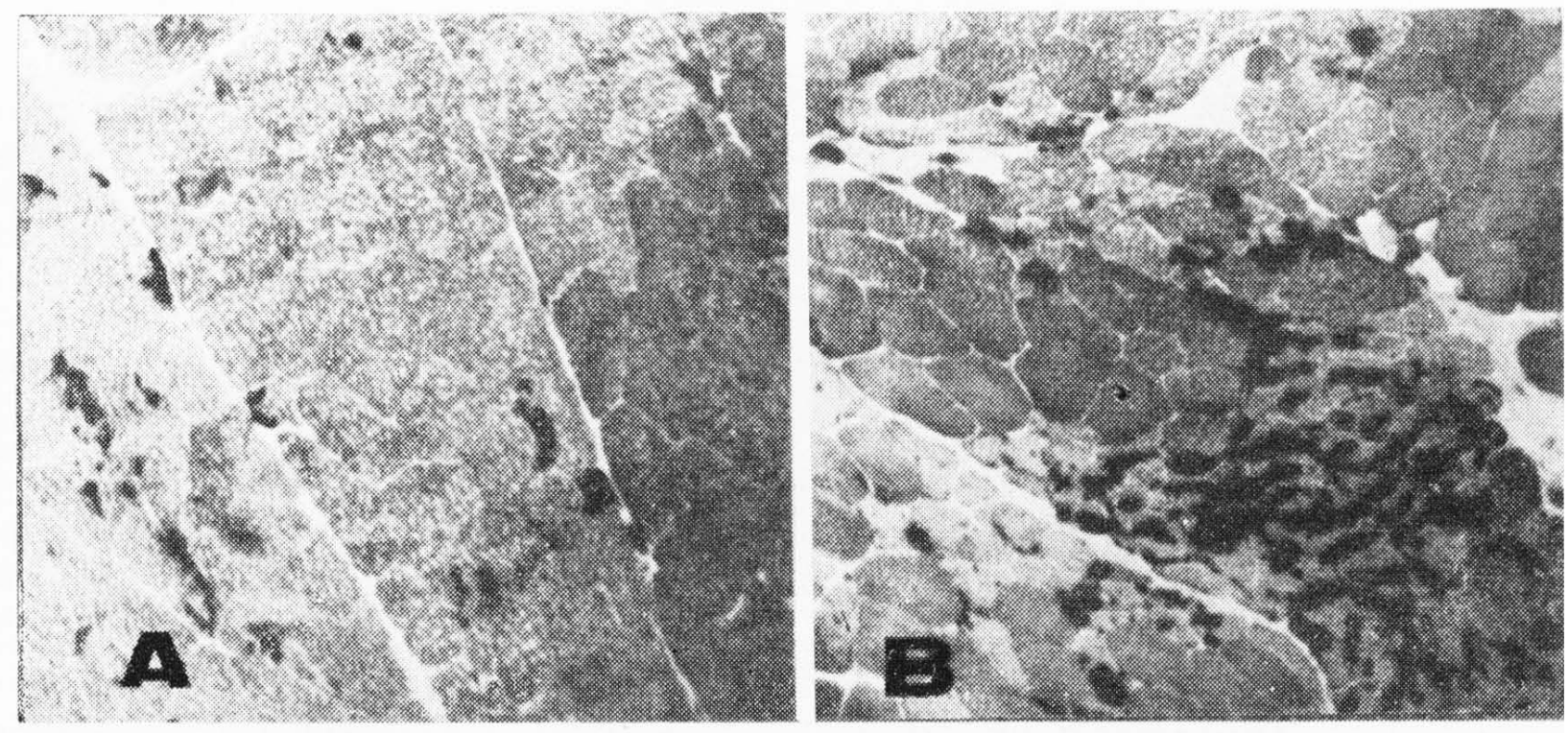

Fig. 3 -... Agregados tubulares em caso de atrofia espinhal crônica proximai,, localizados em fibras do tipo II (DPNH-diaforase, 100X).

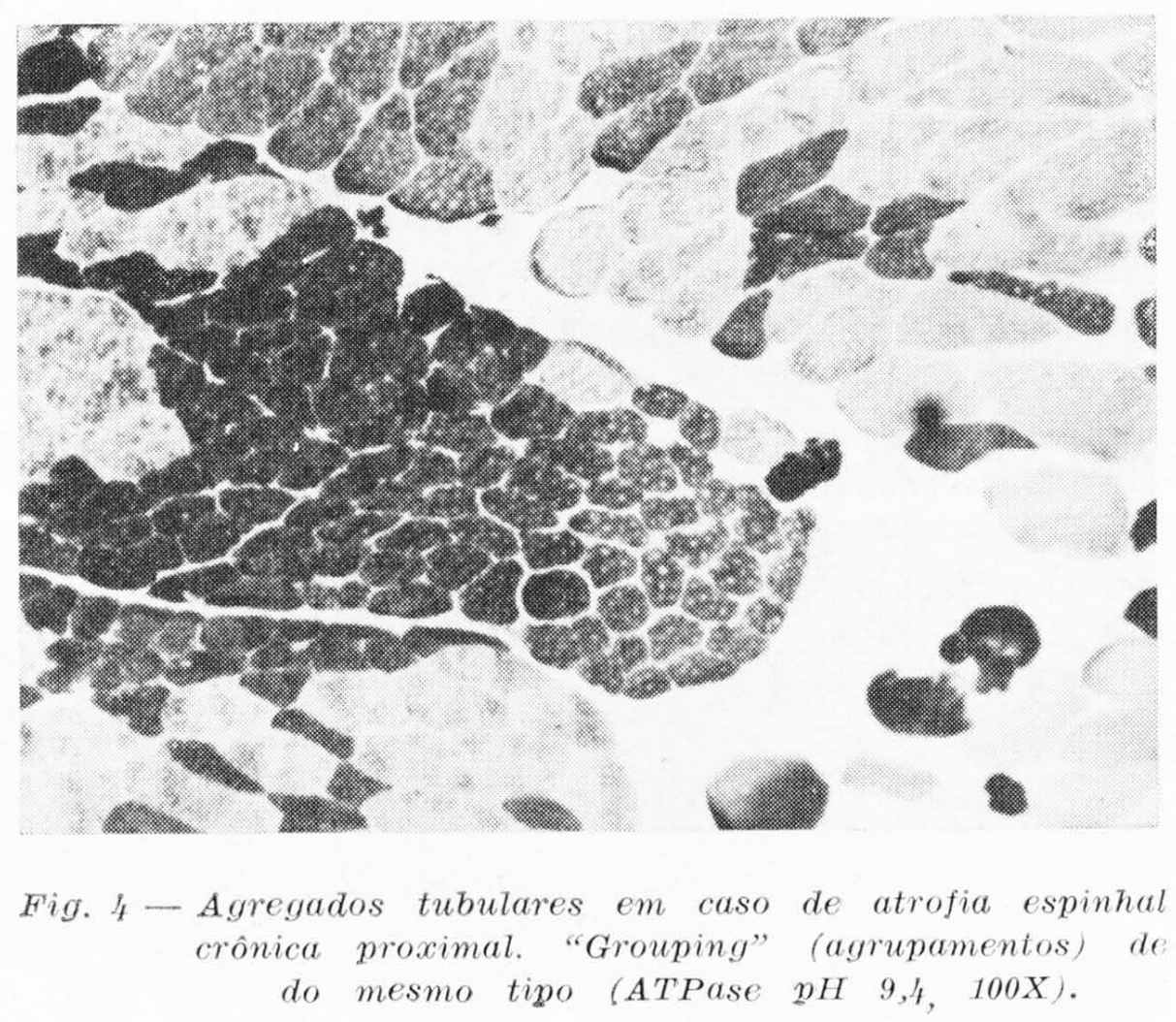

P.A.S. Realizadas as reações para DPNH-diaforase, ATPase pH 4,3, 4,6 e 9,4, fosfatase ácida e alcalina, esterase inespecifica, miofosforilase, desidrogenase succínica, desidrogenase lática.

As biópsias dos músculos quadriceps foram praticamente normais, notando-se apenas discreto aumento do precipitado do formazan à reação pela DPNH-diaforase, próximo às membranas das fibras e se dirigindo para dentro como um rosário, com correspondencia no Gomori modificado com cor avermelhada. A biópsia dos músculos biceps direito e triceps esquerdos foram identicas. Revelaram a presença de estruturas localizadas na periferia das fibras e, às vezes no centro, muito bem evidenciadas 


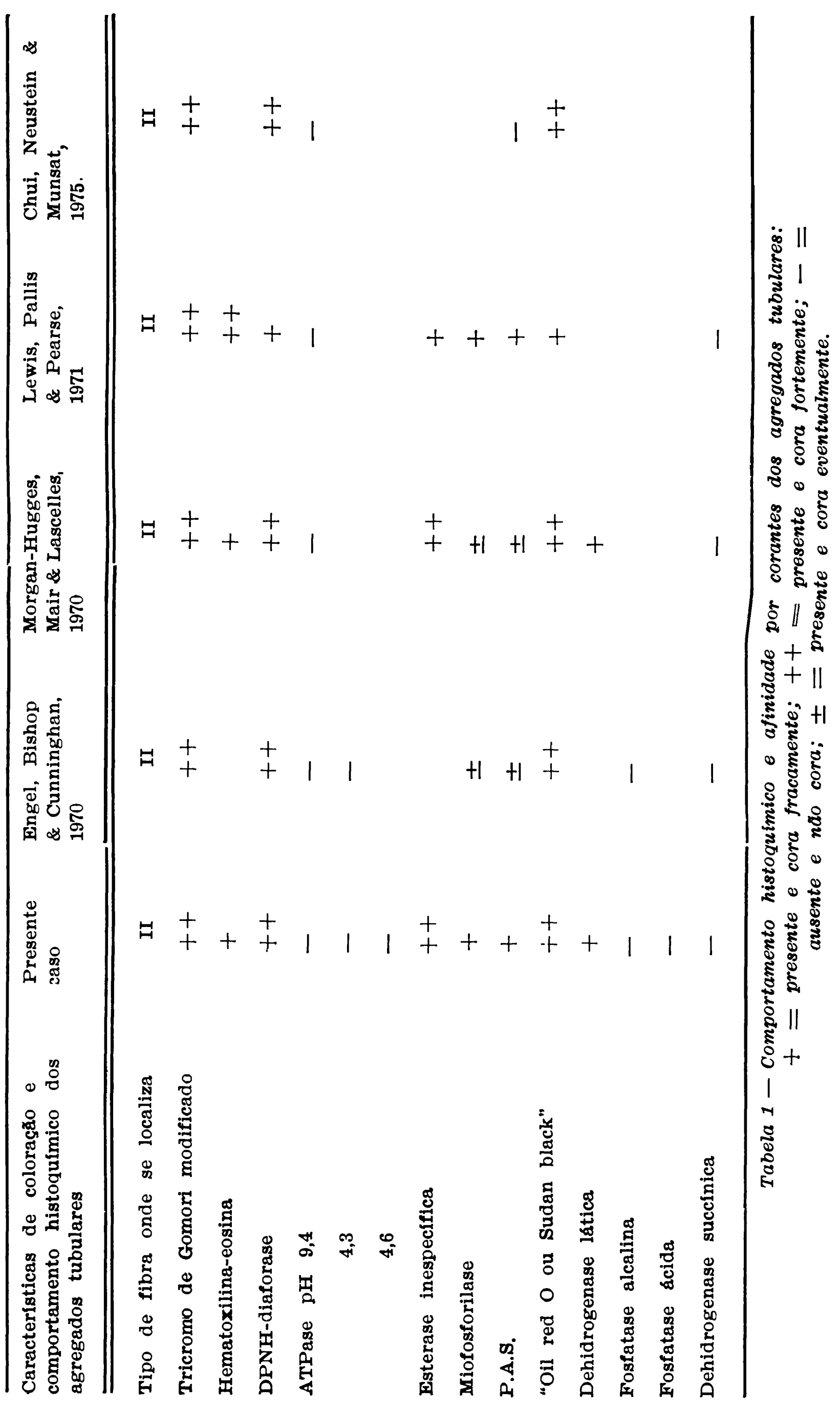


pelo tricromo de Gomori modificado, coradas em vermelho púrpura e na hematoxilinaeosina de cor azul, em menor intensidade (Figura 1). Estas formaçoses eram muito intensas e bem coradas pelo nitro-blue tetrazolium reduzido nas reações pela DPNHdiaforase, com menor intensidade na desidrogenase lática, esterase inespecifica e miofosforilase. Eram negativas, sem corar nas ATPases, fosfatases áciła e alcalina e na desidrogenase succínica. Coravam no P.A.S. e tinham grande afinidade pelo “oil red O" (Figura 2, tabela 1). Estavam localizadas em fibras do tipo II (Figura 3). Além destas estruturas, existiam fibras atróficas, angulares, escuras, coradas fortemente pela DPNH-diaforase e esterase inespecifica. Nas reações para ATPase, foram evidenciados "grouping" (agrupamentos) de fibras do tipo I, IIA e IIB (Figura 4). Estes achados são compatíveis com denervação e reinervaçăo, sendo que as inclusóes anormais comportam-se como agregados tubulares.

\section{COMENTARIOS}

A origem dos agregados tubulares é controvertida, sendo considerados, no início, como derivados das mitocondrias ${ }^{8,14}$; no entanto, ao ser constatada a ausência de succinato desidrogenase e DPN-ligada a alfa-glicerofosfato desidrogenase (enzimas existentes somente dentro das mitocondrias), esta hipótese foi afastada ${ }^{10}$. Pela similaridade morfológica e funcional à microscopia eletrônica, com aumento da captação de ferritina, foram considerados derivados dos túbulos $T^{3,10}$. Ultimamente, ao ser constatada forte reação à DPNH-diaforase $e$ citocromo C oxidase, presença de material amorfo no interior dos túbulos semelhante ao encontrado no retículo sarcoplásmico e invaginação dos mesmos próximo aos agregados tubulares, alguns autores os consideram como derivados do retículo sarcoplásmico ${ }^{3,10}$, acreditando que eles derivam da proliferação lateral ou longitudinal dessas estruturas, embora falte uma prova evidente de relação direta 3,10 .

Se existem dúvidas quanto à sua formação e origem, as incertezas com respeito a sua função e significado são ainda maiores. Tem sido considerados como um processo utilizado pelo músculo para eliminar toxinas exógenas ou endógenas, para corrigir uma situação metabólica anormal ${ }^{3,10}$, uma reação muscular a um processo viral 1,7 ou resposta inespecífica à denervação das fibras musculares do tipo II ${ }^{6}$. Experimentalmente estruturas semelhantes aos agregados tubulares foram produzidas no fígado de animais a partir da proliferação do retículo endoplásmico liso, com aumento da atividade oxidativa, induzida pelo fenobarbital ${ }^{13,17,18,10}$, etanol ${ }^{3,22}$, hidantoinatos ${ }^{22}$ e pelas toxinas tetânica e botulínica ${ }^{6}$. Estruturas semelhantes também foram induzidas durante a denervação experimental 20 e na lesão muscular produzida pelo frio ${ }^{21}$.

Os agregados tubulares foram descritos em diversas doenças, sem que se possa estabelecer uma relação direta com as mesmas. Tem sido descrita com maior frequência nas paralisias periódicas familiares $1,5,7,15$, paralisia periódica tireotóxica ${ }^{1}$, ingestão crônica de drogas (etanol, meperidina, barbitúricos, propoxifeno, diazepan, clorodiazepóxido, fenotiazínicos e ácido para-amino-salicílico) ${ }^{10}$. Também existem relatos de casos em porfiria cutânea tarda ${ }^{10}$, dores com rigidez muscular ${ }^{18}$, miopatia alcoólica ${ }^{3}$, distrofia fascioescapulohumeral com aminoacidúria, miopatia com hiperaldosteronismo ${ }^{12}$, dose excessiva de heroína com rabdomiólise e mioglobinúria, infarto muscular e miastenia gravis tratada com prednisona ${ }^{3}$. Em todas estas doenças, os agregados tubulares ocorreram somente em pacientes do sexo masculino e em fibras musculares do tipo II 9 . 
No nosso caso, encontramos à histoquimica alterações enzimáticas nas inclusões das fibras musculares que as confirmam como agregados tubulares 3,10,14,16, embora o quadro clínico seja de atrofia muscular espinhal crônica proximal 2,4,23. Acreditamos que o uso prolongado de fenobarbital e hidantoínato por 20 anos, o uso moderado e prolongado de álcool etílico e a denervação decorrente da doença básica, foram os fatores predisponentes para a formação dos agregados tubulares. Não acreditamos que os agregados tubulares tenham relação direta com a doença básica do caso aqui descrito.

RESUMO

Relato de um caso de atrofia muscular espinhal crônica proximal em paciente de 35 anos de idade, que apresentava, na biópsia muscular processada pela histoquímica, estruturas identificadas como agregados tubulares. São feitas considerações sobre a patogenia e função dos agregados tubulares. Nó caso descrito, acreditam os autores que os mesmos foram induzidos pelo uso contínuo de anticonvulsivantes por 20 anos, associada à denervação muscular e ao uso constante de álcool.

\section{SUMMARY}

\section{Tubular aggregates in a case of chronic proximal spinal muscle atrophy.}

The case of a 35 years-old man, with chronic proximal muscle atrophy in which at the muscle biopsy tubular aggregates were found by histochemistry procedures is reported. The tubular aggregates stained positive with the modified Gomori trichrome, haematoxylin-eosin, DPNH-diaphorase, non specific esterases, phosphorylase, P.A.S., oil red $O$ and lactate dehydrogenase. They did not show in the routine and acid pre-incubated ATPase, acid and alkaline phosphatases and succinate dehydrogenase. Only found in type II fibers. A brief discussion about the pathogenesis and function of the tubular aggregates is made. The authors believe that the tubular aggregates in this case are secondary to prolonged use of phenobarbital and diphenylhydantoin, associated with the basic denervation process and alcohol abuse.

\section{REFERENCIAS}

1. BERGMAN, R. A.; AFIFI, A. K.; DUNKIE, L. M. \& JOHNS, R. J. - Muscle pathology in hypokalemic periodic paralysis with hyperthyroidism. Hopkins Med. J. $126: 100,1970$.

2. BUNDEY, S. \& LOVELACE, R. E. - A clinical and genetic study of chronic proximal spinal muscular atrophy. Brain 98:445, 1975.

3. CHUI, L. A.: NEUSTEIN, H. \& MUNSAT, T. L. - Tubular aggregates in subclinical alcoholic myopathy. Neurology (Minneapolis) 25:405, 1975.

4. DUBowITz, V. - Benign infantile spinal muscular atrophy. Dev. Med. Child Neurol. $16: 672,1974$.

5. DUBOWITZ, V. \& BROOKE, M. H. - Muscle Biopsy: A Modern Approach. W. B. Saunders Co. Ltd., London, 1973. 
6. DUCHEN, L. W. - The local effects of tetanus toxin on the electron microscopic struture of skeletal muscle fibers of the mouse. J. Neurol. Sci. 19:169, 1973.

7. DUNKLE, L. M.; DIGGS, C. H.; BERGMAN, R. A. \& JOHNS, R. J. - A light and electron microscopic study of a second case of hypokalemic periodic paralysis with hyperthyroidism. Hopkins Med. J. 126:225, 1970.

8. ENGEL, W. K. - Mitochondria aggregates in muscle disease. J. Histoch. Cytochem. $12: 46,1964$.

9. ENGEL, W. K. - Selective and nonselective susceptibility of muscle fiber type. Arch. Neurol. (Chicago) 22:97, 1970.

10. ENGEL, W. K. B BISHOP, D. W. \& CUNNINGHAN, G. C. - Tubular aggregates in type II muscle fibers: ultrastructural and histochemical correlation. J. Ultrastructure Research 31:507, 1970.

11. ENGEL, W. $\mathbf{K} \&$ BROOKE, M. H. - Muscle biopsy as a clinical diagnostic aid. In Fields, W. S. - Neurological Diagnostic Techniques. Charles C. Thomas Publ., Springfield (Illinois), 1966.

12. GALLAI, M. - Myopathy with hyperaldostenonism: an electron-microscopic study. J. Neurol. Sci. 32:337, 1977.

13. JONES, A. L. \& FAWCETT, D. W. - Hypertrophy of the agranular endoplasmic reticulum in hamster liver induced by phenobarbital. J. Histochem. Cytochem. $14: 215,1966$.

14. LEWIS, P. D.; P.ALlis, C. \& PEARSE, A.G.E. - Myopathy with tubular aggregates. J. Neurol. Sci. 13:381, 1971.

15. MACDONALD, R. D.: REWCASTLE, N. B. \& HUMPHREY, J. G. - The myopathy of hyperkalemic periodic paralysis: an electron microscopic study. Arch. Neurol. (Chicago) 19:274, 1968.

16. MORGHAN-HUGHES, J. A.; MAIR, W.G.P. \& LASCELLES, P. T. - A disorder of skeletal muscle associated with tubular aggregates. Brain 93:873, 1970.

17. ORRENIUS, S.; ERICSSON. J. L. E. \& ERNSTER, L. - Phenobarbital-induced synthesis of the microsomal drug-metabolizing enzyme system and its relationship to the proliferation of endoplasmic membranes. J. Cell Biol. 25:627, 1965.

18. ORRENIUS. S. \& ERICSSON. J. L. E. - Enzme-membrane relationship in phenobarbital induction of synthesis of drug-metabolizing enzyme system and proliferation of endoplasmic membranes. J. Cell Biol. 28:181, 1966.

19. ORRENIUS, S. \& ERICSSON, J. L. E. - On the relationship of liver glicose-6phosphatase to the proliferation of endoplasmic reticulum in phenobarbital induction. J. Cell Biol. 31:243, 1968.

20. PELLEGRINO, C. \& FRANZINI, C. - An electron microscope study of denervation atrophy in red and white skeletal muscle fibers. J. Cell Biol. 17:327, 1963.

21. PRICE, H. M.; HOWES, E. L. \& BLUMBERG, J. M. - Ultrastructural alterations in skeletal muscle fibers injured by cold: the acute degenerative changes. Lab. Invest. 13:1264, 1964 .

22. RUBIN, E.; HUTTERER, F. \& LIEBER, C. S. - Ethanol increases hepatic smooth endoplasmic reticulum and drug-metabolizing enzymes. Sciences 159:1469, 1968.

23. VAN WIJNGAARDEN, G. K. \& BETHLEM, J. - Benign infantile spinal muscular atrophy. Brain $96: 163$, 1973.

Disciplina de Neurologia, Departamento de Clinica Médica - Hospital de Clinicas da Universidade Frederal do Parand - Rua General Carneiro 180 - 80000 Curitiba, $P R$ - Brasil. 